\title{
Synthesis of Magnesium Dihydroxide Hybrid Nanocomposites via ATRP
}

\author{
Jeongbin Ok, ${ }^{1,2}$ and Krzysztof Matyjaszewski ${ }^{1,3}$
}

ERRATUM TO: JOURNAL OF INORGANIC

AND ORGANOMETALLIC POLYMERS AND

MATERIALS, VOL. 16, NO. 2 DOI 10.1007/

s10904-006-9043-x

The submitted and accepted dates for this paper were inadvertently omitted. The dates are as follows:

Submitted October 5, 2005; accepted January 13, 2006

The online version of the original article can be found at http:// dx.doi.org/10.1007/s10904-006-9043-x

${ }^{1}$ Department of Chemistry, Center for Macromolecular Engineering, Carnegie Mellon University, 4400 Fifth Avenue, Pittsburgh, PA, 15213, USA.

2 LG Cable Research Lab., 555 Hogye, Dongan, Anyang, Gyeonggi, 431-749, Korea.

${ }^{3}$ To whom correspondence should be addressed.

E-mail: km3b@andrew.cmu.edu 